\title{
Day Care Monitor Dies After Crash of 15-Passenger Van
}

\section{Incident Number: 12KY026}

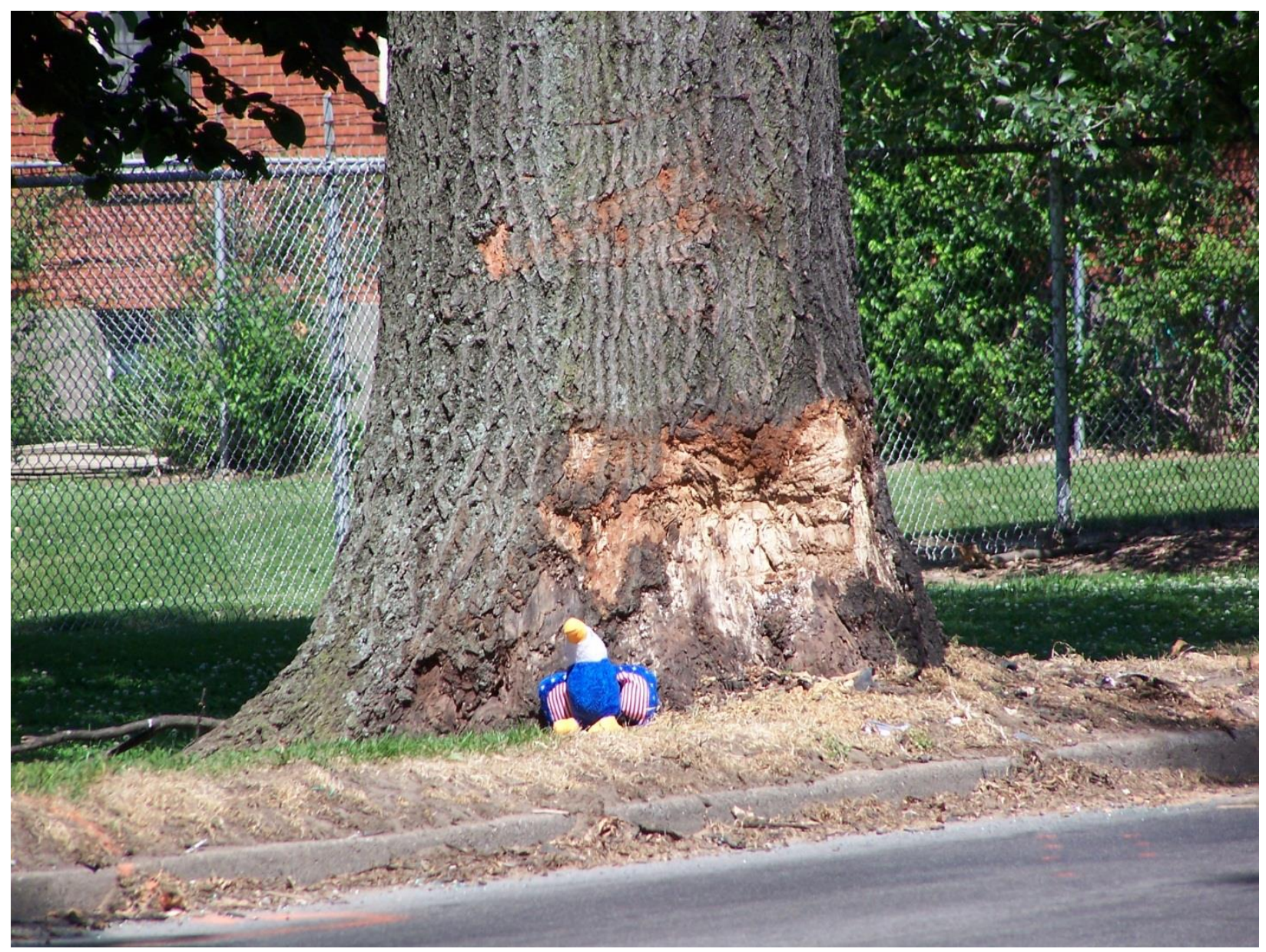

The tree involved in the crash. Photos included in this report are property of Kentucky FACE.

Kentucky Fatality Assessment and Control Evaluation Program Kentucky Injury Prevention and Research Center 333 Waller Avenue

Suite 242

Lexington, Kentucky 40504

Phone: 859-323-2981

Fax: 859-257-3909

www.kiprc.uky.edu

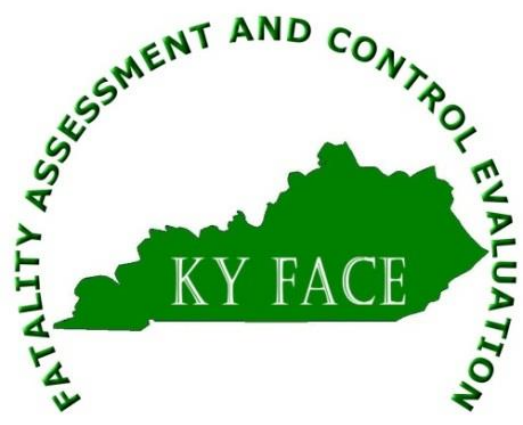




\section{Kentucky Fatality Assessment and Control Evaluation (FACE) Program \\ Incident Number: 12KY026 \\ Release Date: June 2013 \\ Subject: Day Care Monitor Dies After Crash of 15-Passenger Van}

\section{Summary}

In the late afternoon of a spring day, a day care van operator and a monitor loaded 16 children into a 15-passenger van. Carrying a total of 18 passengers in the 15-passenger van, the operator and the monitor proceeded to transport the children to their homes. After dropping off two children at their residences, the van was traveling 46-50 mph in the left hand lane headed east in a $35 \mathrm{mph}$ zone on a non-divided four-lane state road. As the van approached a side street on the right, the right rear tire blew out and the van veered sharply to the left, crossing over two westbound lanes and striking a tree head-on. Witnesses called emergency services and began extracting the children, operator, and monitor from the van. All occupants were transported to local hospitals for treatment of injuries. The monitor died at the hospital; the operator and all other passengers survived.

To prevent future occurrences of similar incidents, the following recommendations have been made:

Recommendation No. 1: Daycare facilities that utilize 15-passenger vans should ensure operators are properly trained in safe vehicle operations.

Recommendation No. 2: Daycare facility owners should ensure company vehicles have routine maintenance and inspections performed.

Recommendation No. 3: Daycare employees involved in the transportation of children must follow all the transportation rules and laws that apply.

Recommendation No. 4: Kentucky daycare facilities should use alternatives to 15passenger vans to transport children for the safety of the children and the daycare employees.

Recommendation No. 5: Kentucky should authorize one agency to oversee daycare transportation operations.

Recommendation No. 6: Manufacturers should improve the safety of 15-passenger vans, especially since they are often used to transport children.

\section{Background}

A 31-year-old female daycare worker was a van monitor and assisted the 37-year-old van driver in transporting children to and from the daycare facility in a 15-passenger van. Both the driver 
and the monitor had been trained in child transportation by the daycare owner. Occasionally the owner would ride in the van while the driver made her rounds. There were three daycare facilities in close proximity to each other owned by the same person.

The driver had been employed by the daycare for approximately one year. She had originally been hired as a van monitor but had been driving the van for several months prior to the crash. The monitor had been employed for several months. Most days, the driver and monitor reported for work between 2:00 and 3:00 p.m. and began their rounds shortly thereafter. There were occasions when the driver transported children without a monitor. It is unknown if morning transportation was provided by the daycare facility.

Purchased used from a dealer, the 15-passenger van was a 2009 model with front wheel drive. Prior to the daycare owner purchasing it, the van was involved in a crash in a parking lot and had sustained minor damage. It was reported that oil changes were performed on a regular basis. It is unknown if tire pressure monitoring and rotation were routinely performed.

Weather on the day of the crash was clear and temperatures ranged from 68 degrees Fahrenheit to 86 degrees Fahrenheit. No precipitation had occurred in the 24 hours prior to the crash.

\section{Investigation}

The Kentucky Fatality Assessment and Control Evaluation program was informed via a news broadcast of a crash involving a 15-passenger van operated by a daycare and that the van monitor had died due to the crash. FACE personnel traveled to the scene and took photographs of the location where the crash occurred. Interviews with the police were conducted. Attempts by KY FACE personnel to interview the owner of the daycare were not answered.

Between 2:00 and 3:00 p.m. on a late spring day, a female van driver and a female monitor arrived for work at a daycare. Around 4:00 p.m., they loaded 16 children into a 15-passenger van. Behind the driver and front passenger seats, there were three rows of three seats, then a fourth row of four seats at the back of the van. Each seat was equipped with a personal restraint safety belt. With the driver in the driver's seat, the monitor seated herself, restrained, in the front passenger seat.

The driver proceeded out of the daycare's parking lot and dropped off two children at their residences, leaving 14 children and 2 adults still in the van. As they drove toward another child's residence, the van was in the left hand lane, traveling approximately 46-50 miles per hour, headed east on a straight stretch of a four lane road. East and westbound lanes were divided by a double yellow line. The roadway was flat and the pavement was dry; the speed limit was 35 miles per hour, and traffic was normal. It was approximately 5:10 p.m. when the right rear tire failed. Upon failure of the tire, the van became uncontrollable and it veered left, crossing both westbound lanes, striking a tree head-on and causing the front axle to break.

A witness to the crash stopped to assist and called emergency medical services (EMS) to the scene. When EMS arrived, witnesses had already removed some of the children from the van. 
The driver was belted in the driver's seat, and they found the van monitor between the second and third row seats. EMS transported the 14 children, driver and monitor to local hospitals. The driver and all 14 children sustained a variety of injuries, some severe, but survived. The monitor was declared dead at the hospital.

The reconstruction of the incident revealed damage had occurred in the middle of the rear right tire sometime prior to the crash and the interior tire belt had broken. Also, the tires on the van had less than $2 / 16$ " tread. There was no evidence of braking after the tire failed. Both front airbags were reported to have deployed upon impact with the tree. A passenger manifest was not located in the van, nor could one be found at the office of the daycare. It was reported by a witness that four children had been secured together with one restraint system. This would follow from the fact that the capacity of the van had been exceeded by 3 passengers at trip outset. The driving record of the van operator prior to the crash is unknown.

\section{Cause of Death}

The monitor's cause of death was due to internal injuries and blunt force trauma resulting from a motor vehicle crash.

\section{Recommendations and Discussion}

\section{Recommendation No. 1: Daycare facilities that utilize 15-passenger vans should ensure operators are properly trained in safe vehicle operations.}

Drivers must be aware that 15-passenger vans handle differently than passenger cars, especially during an emergency like a tire blow out. Operators of 15-passenger vans should receive special driver training and should optimally carry a commercial driver's license. Not only should the operator be trained on how to check proper tire inflation and wear, they should be trained on loading techniques and restrictions. According to the SaferCar.gov website, 15-passenger vans should never have more than 15 occupants in the van (including the driver). Overloading of a 15-passenger van makes the vehicle more unstable and difficult to handle, especially in a crash situation. Improper loading also makes the vehicle more prone to rolling over. Every passenger, including operators and monitors, should utilize personal restraint systems in 15-passener vans. Only one occupant per restraint system should be allowed. Manifest logs, detailing the identities of vehicle occupants at all times, should be maintained and kept in the vans.

\section{Recommendation No. 2: Daycare facility owners should ensure company vehicles have routine maintenance and inspections performed.}

According to the crash scene reconstructionist, the tires on the van had less than 2/16" tread, and there had been damage to the middle of the failing tire (cause unknown) prior to the crash. It was the prior damage which caused the tire to fail. The National Highway Traffic Safety Administration (NHTSA) states that tires on 15-passenger vans should be checked every trip for accurate tire pressure, and wear. Tires should be replaced when tread is less than $2 / 16$ " 
(SaferCar.gov). The National Transportation Safety Board (NTSB) issued a Safety Alert about 15-passenger vans pointing out that front and back tires may require different inflation pressures with pressures of up to $50 \mathrm{lbs}$. in the front tires and up to $80 \mathrm{lbs}$. in the rear tires. According to the NTSB, a major problem with 15-passenger vans is that their tires are often underinflated, leading to higher tire temperatures, faster tire deterioration, and diminished driving stability. All of these factors may have been involved in this incident.

Daycare centers should require pre- and post- trip inspections of vans prior to each use. Inspections should document tire pressure, tire wear, window conditions, required repairs, etc. The Federal Motor Carrier Safety Administration Driver's Vehicle Inspection form for commercial drivers should be adapted for 15-passenger vans. See Attachment 1.

\section{Recommendation No. 3: Daycare employees involved in the transportation of children must follow all the transportation rules and laws that apply.}

Numerous traffic rules were not observed by the daycare van driver and monitor. The driver of the daycare van was speeding at the time of the incident, driving 46-50 $\mathrm{mph}$ in a $35 \mathrm{mph}$ zone. There were too many occupants in the van making it impossible to restrain each rider properly and contributing to the lack of stability of the vehicle. Children and adults were not properly restrained in individual restraint systems with reports of 4 children in one restraint and adult riders possibly unrestrained. Each of these offenses could have contributed to the severity of the injuries sustained by all involved in the crash.

\section{Recommendation No. 4: Kentucky daycare facilities should use alternatives to 15- passenger vans to transport children for the safety of the children and the daycare employees.}

Because of the natural instability of 15-passenger vans, the state of Kentucky prohibits the use of 15-passenger vans by public schools to transport children. Daycare facilities should observe this restriction and use school buses or vehicles meeting school bus requirements (i.e., flashing lights, stop arms, increased structural standards) to transport children. National Health and Safety Performance Standards for childcare facilities state that the use of 15-passenger vans should be avoided whenever possible. NHTSA further states that pre-primary, primary and secondary schools should not use 15-passenger vans for transporting school children, as they do not provide the same level of safety as school buses. The 2005 federal highway reauthorization act prohibits public pre-primary, primary, and secondary schools from purchasing, renting or leasing new 15passenger vans for transporting students unless the vans meet the federal standards for school buses. In Kentucky, 15-passenger vans can still be purchased and used by daycare facilities to transport children.

\section{Recommendation No. 5: Kentucky should authorize one agency to oversee daycare transportation operations.}

Currently oversight of daycare operations falls under the jurisdiction of several agencies and departments within the state of Kentucky. Furthermore, no one entity oversees the transportation of children and employees by a daycare operation. If transportation is provided by the daycare, 
the vehicle is inspected yearly by the Commercial Motor Vehicle Division. However, there is no entity ensuring that this is being done. The owner of the daycare told the reconstructionist that the van had passed inspection, but there was no documentation to support that claim. Research also indicated that the daycare owner had her transportation license revoked at one facility but was then able to obtain a transportation license when she opened another facility. Similar to the Federal Motor Carrier Safety Administration's (FMCSA) prohibition against chameleon carriers, daycare owners should not be able to obtain a new transportation license when an existing one has been revoked for safety violations.

\section{Recommendation No. 6: Manufacturers should improve the safety of 15-passenger vans, especially since they are often used to transport children.}

Internal records indicate as early as the mid-1970's, engineers recognized the need to extend the wheelbase and add dual rear wheels to increase the stability of 15-passenger vans. Tests have shown that dual rear wheels give enough additional rear traction to prevent loss of control in most driving emergencies. Dual rear wheels also offer the protection of an extra tire on each side so that sudden failure of one tire is less likely to result in loss of control. Dual rear wheels may have prevented the death of the daycare monitor and the injuries of many children in the incident described in this report.

\section{Keywords}

15-passenger van

Day care

Monitor

Operator

\section{References}

www.nhtsa.gov/CA/10-14-2010

http://www.safercar.gov/Vehicle+Shoppers/Resources/15-Passenger+Van+Safety

http://www.ntsb.gov/doclib/safetyalerts/sa_001.pdf

http://www.stnonline.com/resources/safety/non-conforming-vans

Federal Motor Carrier Safety Administration

SafetyBeltSafe U.S.A., "Safe Rides to Day Care", \#653, 7-24-07

"Legal But Lethal: The 15-Passenger Van", Chris Glover

Caring for Our Children: National Health and Safety Performance Standards, Third Edition

American Academy of Pediatrics, American Public Health Association and National Resource

Center for Health and Safety in Child Care and Early Education, 2011 


\section{Acknowledgements}

The Kentucky FACE program would like to thank the local police department for their assistance with this report.

The Pediatric and Adolescent Injury Prevention Program at KIPRC contributed to the development of this report and its recommendations through their work on the child care transportation, regulation and inspection process.

The Kentucky Fatality Assessment \& Control Evaluation Program (FACE) is funded by grant 2U60OH008483-09 from the Centers for Disease Control and the National Institute for Occupational Safety and Health. The purpose of FACE is to aid in the research and prevention of occupational fatalities by evaluating events leading to, during, and after a work related fatality. Recommendations are made to help employers and employees have a safer work environment. For more information about FACE and KIPRC, please visit our website at: www.kiprc.uky.edu 
Attachment 1: Copy of Department of Transportation Daily Driver's Vehicle Inspection Report

\section{DRIVER'S VEHICLE INSPECTION REPORT}

CARRIER:

ADDRESS:

DATE:

TIME:

A.M. CHECK ANY DEFECTIVE ITEM AND GIVE DETAILS UNDER “REMARKS" P.M.

TRACTOR/

TRUCK NO.

$\square$ Air Compressor
$\square$ Air Lines
$\square$ Battery
$\square$ Body
$\square$ Brake Accessories
$\square$ Brakes, Parking
$\square$ Brakes, Service
$\square$ Clutch
$\square$ Coupling Devices
$\square$ Defroster/Heater
$\square$ Drive Line
$\square$ Engine
$\square$ Exhaust
$\square$ Fifth Wheel
$\square$ Frame and Assembly
$\square$ Front Axle
$\square$ Fuel Tanks
$\square$ Generator

ODOMETER READING

$\begin{array}{ll}\square \text { Horn } & \square \text { Suspension System } \\ \square \text { Lights } & \square \text { Starter } \\ \text { Head - Stop } & \square \text { Steering } \\ \text { Tail - Dash } & \square \text { Tachograph } \\ \begin{array}{c}\text { Turn Indicators } \\ \text { Mirrors }\end{array} & \square \text { Tires } \\ \square \text { Muffler } & \square \text { Tire Chains } \\ \square \text { Oil Pressure } & \square \text { Transmission } \\ \square \text { Radiator } & \square \text { Wheels and Rims } \\ \square \text { Rear End } & \square \text { Windows } \\ \square \text { Reflectors } & \square \text { Other }\end{array}$

TRAILER(S) NO.(S)

$\begin{array}{lll}\square \text { Brake Connections } & \square \text { Hitch } & \square \text { Tarpaulin } \\ \square \text { Brakes } & \square \text { Landing Gear } & \square \text { Tires } \\ \square \text { Coupling Devices } & \square \text { Lights - All } & \square \text { Wheels and Rims } \\ \square \text { Coupling (King) Pin } & \square \text { Roof } & \square \text { Other } \\ \square \text { Doors } & \square \text { Suspension System } & \\ \text { Remarks: } & & \end{array}$

Safety Equipment

Fire Extinguisher

Reflective Triangles

Flags - Flares - Fusees

Spare Bulbs \& Fuses

Spare Seal Beam

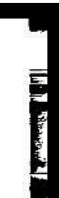

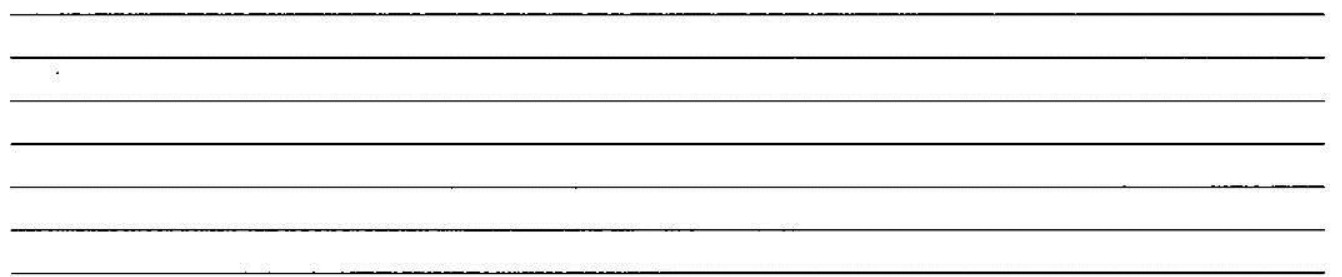

$\square$ CONDITION OF THE ABOVE VEHICLE IS SATISFACTORY

DRIVER'S SIGNATURE:

$\square$ ABOVE DEFECTS CORRECTED

$\square$ ABOVE DEFECTS NEED NOT BE CORRECTED FOR SAFE OPERATION OF VEHICLE

MECHANIC'S SIGNATURE: DATE

DRIVER'S SIGNATURE: DATE

ORIGINAL 


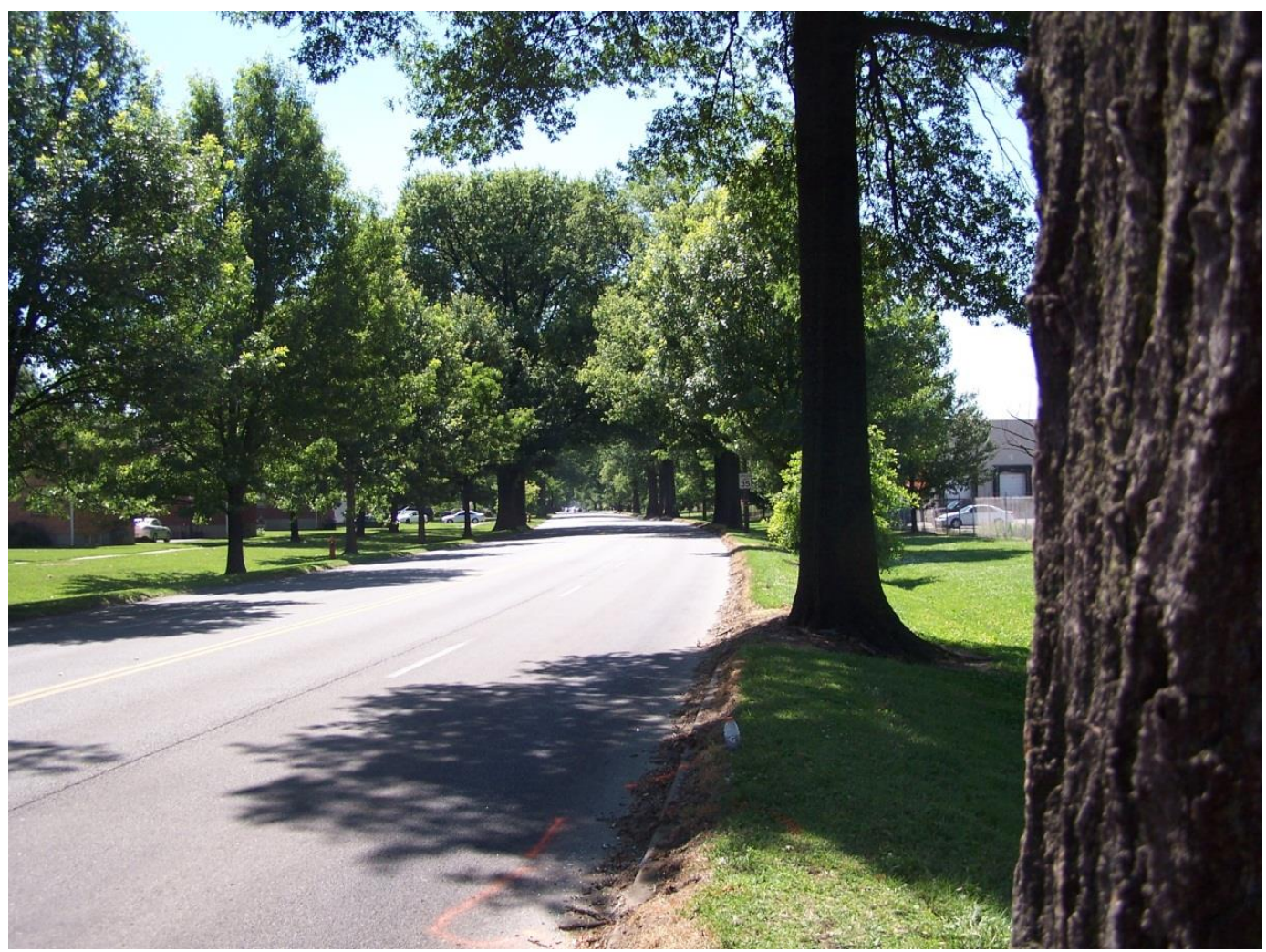

Street scene from the spot where the van crashed into the tree.

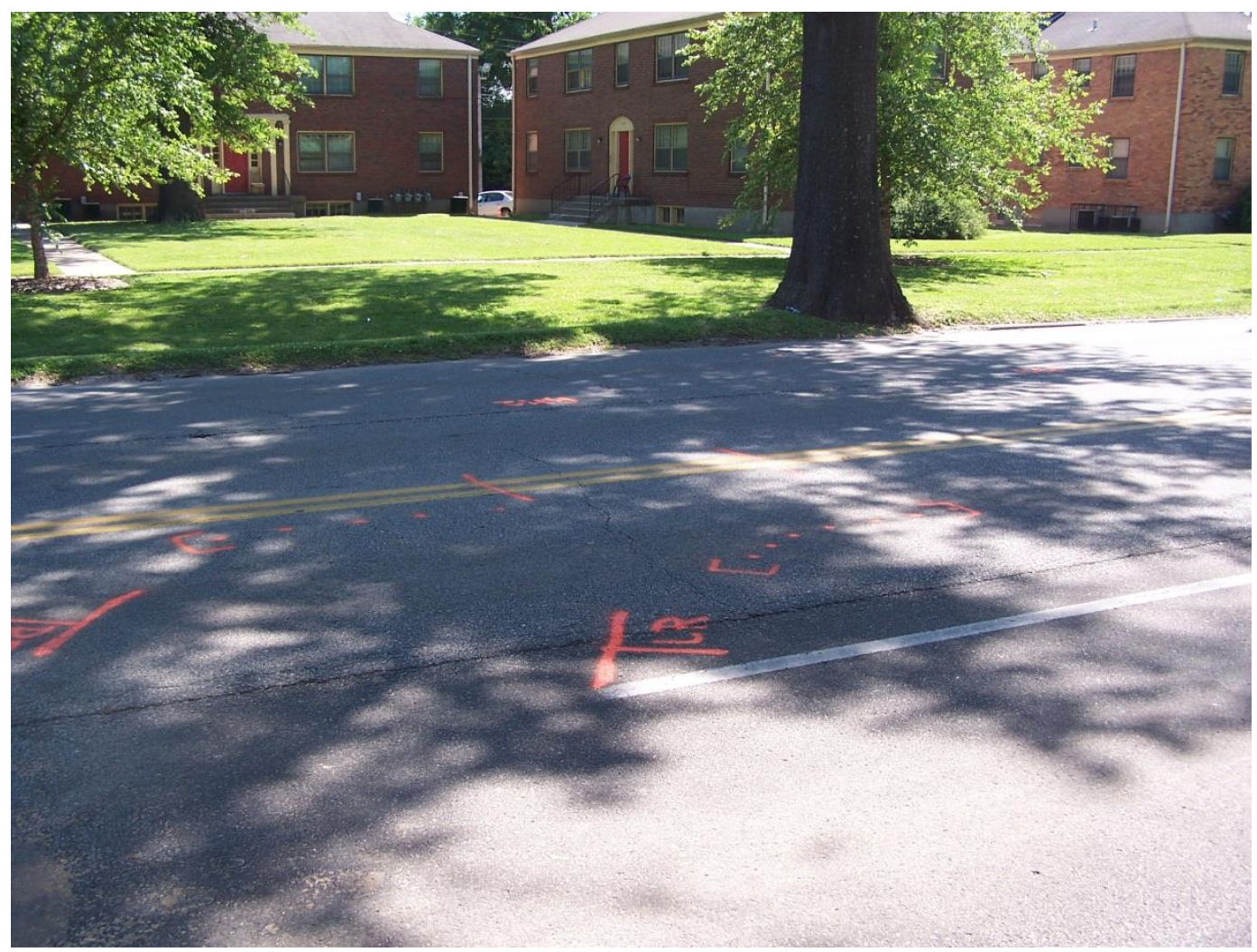

Markings show path of the van after the tire blowout, crossing into westbound lanes. 